\title{
Prevalence and Factors Associated with Anxiety and Depression in Expectant Mothers at Parakou in 2018
}

\author{
Anselme Djidonou ${ }^{{ }^{*}}{ }^{\circledR}$, Francis Tognon Tchegnonsi ${ }^{1}$, Christel Crédo Mahugnon Ahouandjinou ${ }^{1}$, \\ Boris Houinou Ebo' ${ }^{1}$, Covali Melic Bokossa², Jivaterd Degla1, Emilie Fiossi-Kpadonou ${ }^{3}$ \\ ${ }^{1}$ Medicine and Medical Specialties Department, Faculty of Medicine, University of Parakou, Parakou, Benin \\ ${ }^{2}$ National School for Higher Technicians Training in Public Health and Epidemiology (ENATSE), University of Parakou, \\ Parakou, Benin \\ ${ }^{3}$ Faculty of Health Sciences, University of Abomey-Calavi, Abomey-Calavi, Benin \\ Email: *cmpjubile2000@gmail.com,vraaru.uac@uac.bj
}

How to cite this paper: Djidonou, A., Tognon Tchegnonsi, F., Ahouandjinou, C.C.M., Houinou Ebo, B., Bokossa, C.M., Degla, J. and Fiossi-Kpadonou, E. (2019) Prevalence and Factors Associated with Anxiety and Depression in Expectant Mothers at Parakou in 2018. Open Journal of Psychiatry, 9, 235-247.

https://doi.org/10.4236/ojpsych.2019.93018

Received: April 24, 2019

Accepted: July 2, 2019

Published: July 5, 2019

Copyright $\odot 2019$ by author(s) and Scientific Research Publishing Inc. This work is licensed under the Creative Commons Attribution International License (CC BY 4.0).

http://creativecommons.org/licenses/by/4.0/

\begin{abstract}
Background: Anxiety and depressive disorders can disturb the development of pregnancies. The goal was to study the prevalence and factors associated with anxiety and depression in expectant mothers followed in public maternity wards of Parakou in 2018. Population and methods: It was a crosssectional study which consisted in an exhaustive census and a consecutive recruitment of 835 expectant mothers from June 14th to September 14th, 2018. Data collection was realized through interview between the investigator and the respondent basing on a questionnaire in which were integrated Edinburgh Postnatal Depression Scale-3 (EPDS-3), EPDS and modular Integrated Household Living Conditions Survey (IHLCS-2015) to assess respectively anxiety, depression and expectant mothers' socio-economic level. Results: The prevalences of anxiety and depression were respectively $44.91 \%$ and $35.33 \%$. Many factors were associated with anxiety and depression. Low socio-economic level increased 6.7 times the risk of developing anxiety $(\mathrm{OR}=$ 6.70; $\left.\mathrm{IC}_{95 \%}[2.83-13.00] ; p=0.000\right)$ and 8.64 times the risk for the onset of depression $\left(\mathrm{OR}=8.64 ; \mathrm{IC}_{95 \%}[3.09-17.18] ; p=0.000\right)$. Celibacy increased 2.67 times the risk of developing anxiety $\left(\mathrm{OR}=2.67 ; \mathrm{IC}_{95 \%}[1.19-5.98] ; p=\right.$ $0.000)$ and 2.18 times the one of depression $\left(\mathrm{OR}=2.18 ; \mathrm{IC}_{95 \%}[1.07-4.40] ; p\right.$ $=0.000$ ). Low economic level and celibacy were the main psychosocial determinants of anxiety and depression in expectant mothers. Conclusion: The implementation of multidisciplinary action program centred on improving purchasing power would reduce the risk of anxiety and depression in expectant mothers.
\end{abstract}




\section{Keywords}

Anxiety, Depression, Social Determinants, Expectant Mothers

\section{Introduction}

Pregnancy and childbirth allow women to access the status of mother. But, the physiological and psychosomatic modifications induced during that period weaken the woman and expose her to many psychiatric disorders including anxiety and depression. Their onset during pregnancy constitutes a risk for both the mother and the child. About $10 \%$ of pregnant women are affected [1] [2]. At least, one expectant mother out of ten coming at the regular appointments for pregnancy follow-up is or will be depressed. However, very few of them are diagnosed. They refrain from revealing their feelings or consulting a health care professional due to the symptoms minimization or the stigma attached to mental health issues. During pregnancy, the pre-existing psychotic disorders can resurface, like a substance abuse or a suicide attempt when they are combined with an undesired pregnancy. According to Gourine et al. [3], more than 15 years as duration of diabetes is predictive of developing a depression during pregnancy. Depression rates are also high at the end of the pregnancy and during postpartum. Postpartum depression affects more than $15 \%$ of new mothers [4].

In Benin and particularly at Parakou, no study was submitted on psychiatric disorders during pregnancy and puerperium. That is the reason for this study.

\section{Population and Methods}

\subsection{Type and Period of the Study}

It was a cross-sectional study with analytical aim and prospective data collection of all the expectant mothers followed from June 14th to September 14th, 2018 in Parakou maternity wards.

\subsection{Population and Inclusion Criteria}

The sample size was the sum of the encountered expectant mothers who have given their prior consent during data collection. Non available expectant mothers were excluded. A total number of 835 expectant mothers was retained.

\subsection{Study Variables}

The dependent variables were related to anxiety and depression.

The independent variables were related to sociodemographic and gynaecoobstetrical factors; a previous psychological vulnerability such as personal and family history of psychiatric disorders, abuse or rape in childhood; psychosocial factors during pregnancy and personal history such as the desire of pregnancy, existence of marital conflicts, a child or a close relative death, a stressful life event during pregnancy, the absence of social support, Difficulties or pathologies 
about the current pregnancy, the lesser follow-up of the pregnancy; risky maternal behaviour; alcohol, tobacco and others psychoactive substances consumption.

\subsection{Data Collection Tools and Technique}

Data collection was realized through individual semi-structured interviews basing on a questionnaire in which were integrated the scales: Edinburgh Postnatal Depression Scale-3 (EPDS-3), EPDS [5] and modular Integrated Household Living Conditions Survey (IHLCS-2015) [6] to assess respectively anxiety, depression (the threshold value used to assess depression was 11 and 4 for anxiety) and expectant mothers' socio-economic level 5 (SEL: high SEL $=$ total score $\geq$ $85 \%$, average SEL $=50 \% \leq$ total score $\leq 85 \%$, low SEL $=$ total score $\leq 50 \%)$. The scales used in the study were translated and validated for local population.

\subsection{Ethical Considerations and Data Processing}

The study follows a medical thesis. It has been conducted after the approval from the local research ethics board and biomedical research of Parakou University. The data collection was carried out through a semi-structured individual interview using a pre-tested questionnaire, in accordance with the ethical principles set out in the Helsinki Declaration of the Medical World [7]; the informed consent of the respondents was required, as well as the preservation of their anonymity. Data have been collected on a sheet survey by the personnel who usually perform the childbirth at the survey location and recycled for the circumstance.

For the study of association's stability between anxiety, depression and the different factors, a univariate analysis $(p<0.05)$ was simultaneously included in a logistic regression model using a downward and step by step successive iterations. The comparison of factors percentages between dependent variables and the factors associated was made basing on a "chi-2" test. The association strength, meaning and stability were estimated using Odd ratios and $95 \%$ as their confidence intervals. The significance level was set at $5 \%$.

\section{Results}

\subsection{Prevalence of Anxiety and Depression in Encountered Expectant Mothers}

According to the scales EPDS 3A and EPDS, the number of the survey respondents having an anxiety or a depression was respectively 375 (44.91\%) and 295 (35.33\%).

\subsection{Factors Associated with Anxiety}

The mean age of the interviewed expectant mothers was $25 \pm 5.1$ years with the extremes 15 and 45 years. The age group 15 to 24 years was the most represented $(47.12 \%)$. The socioeconomic level and the previous onset of a spontaneous 
miscarriage is associated with anxiety in the interviewed expectant mothers. Table 1 and Table 2 present the factors associated with anxiety in encountered expectant mothers.

\subsection{Factors Associated with Depression}

The educational level and difficulties during pregnancy were associated with depression in expectants mothers. Table 3 and Table 4 show the factors associated with depression in the encountered expectant mothers.

\subsection{Determinants of Anxiety in Encountered Expectant Mothers}

In the multivariate logistic regression, low socioeconomic level, third trimester of pregnancy respectively increase 6.70 times and 2.47 times the risk of developing anxiety. Table 5 shows the determinants of anxiety during pregnancy in expectant mothers.

\subsection{Determinants of Depression in the Encountered Expectant Mothers}

In this multivariate logistic regression, low socioeconomic level increases 8.64 times the risk of developing depression. Table 6 presents psychosocial determinants of depression during pregnancy in expectant mothers.

Table 1. Distribution of patients by profession, marital status, socioeconomic level and previous onset of spontaneous miscarriage, according to anxiety. (Parakou, 2018; $\mathrm{N}=$ 835).

\begin{tabular}{|c|c|c|c|c|c|c|}
\hline & \multicolumn{4}{|c|}{ ANXIETY } & \multirow{3}{*}{$\begin{array}{c}\text { Total } \\
(\mathrm{N})\end{array}$} & \multirow{3}{*}{$p$} \\
\hline & \multicolumn{2}{|c|}{ Yes } & \multicolumn{2}{|c|}{ No } & & \\
\hline & $\mathrm{n}$ & $\%$ & $\mathrm{n}^{\prime}$ & $\%$ & & \\
\hline Profession & & & & & & 0.016 \\
\hline Official & 8 & 26.67 & 22 & 73.33 & 30 & \\
\hline Private sector worker & 32 & 32.65 & 66 & 67.35 & 98 & \\
\hline Trader/Reseller & 115 & 43.56 & 149 & 56.44 & 264 & \\
\hline Artisan & 108 & 47.79 & 118 & 52.21 & 226 & \\
\hline Pupil/student & 45 & 48.91 & 47 & 51.09 & 92 & \\
\hline Unemployment & 60 & 53.10 & 53 & 46.90 & 113 & \\
\hline Others & 7 & 58.33 & 5 & 41.67 & 12 & \\
\hline Marital status & & & & & & 0.005 \\
\hline Single & 17 & 45.95 & 20 & 54.05 & 37 & \\
\hline cohabitation & 162 & 38.85 & 255 & 61.15 & 417 & \\
\hline Married & 195 & 51.45 & 184 & 48.55 & 379 & \\
\hline divorced & 1 & 100.00 & 0 & 0.00 & 1 & \\
\hline Widow & 0 & 0.00 & 1 & 100.00 & 1 & \\
\hline
\end{tabular}




\section{Continued}

\begin{tabular}{ccccccc}
\hline Socioeconomic Level & & & & & & 0.000 \\
Low & 251 & 47.36 & 279 & 52.64 & 530 & \\
Average & 116 & 47.74 & 127 & 52.26 & 243 & \\
High & 8 & 12.90 & 54 & 87.10 & 62 & \\
Spontaneous Miscarriage & & & & & & 0.001 \\
Yes & 50 & 29.41 & 120 & 70.59 & 170 & \\
No & 119 & 44.74 & 147 & 55.26 & 266 & \\
\hline
\end{tabular}

Table 2. Distribution of encountered expectant mothers by previous onset of an induced abortion, absence of social support, gestational age, dear parent or perinatal death, abuse or rape in childhood, according to anxiety. (Parakou, 2018; $\mathrm{N}=835$ ).

\begin{tabular}{|c|c|c|c|c|c|c|}
\hline & \multicolumn{4}{|c|}{ ANXIETY } & \multirow{3}{*}{$\begin{array}{l}\text { Total } \\
\text { (N) }\end{array}$} & \multirow{3}{*}{$p$} \\
\hline & \multicolumn{2}{|c|}{ Yes } & \multicolumn{2}{|c|}{ No } & & \\
\hline & $\mathrm{n}$ & $\%$ & $\mathrm{n}^{\prime}$ & $\%$ & & \\
\hline Induced Miscarriage & & & & & & 0.023 \\
\hline Yes & 18 & 26.47 & 50 & 73.53 & 68 & \\
\hline No & 151 & 41.03 & 217 & 58.97 & 368 & \\
\hline Absence of social suppor & & & & & & 0.022 \\
\hline Yes & 32 & 60.38 & 21 & 39.62 & 53 & \\
\hline No & 343 & 43.86 & 439 & 56.14 & 782 & \\
\hline Gestational age & & & & & & 0.000 \\
\hline 1 st trimester & 54 & 31.03 & 120 & 68.97 & 174 & \\
\hline 2nd trimester & 143 & 44.27 & 180 & 55.73 & 323 & \\
\hline 3rd trimester & 178 & 52.66 & 160 & 47.34 & 338 & \\
\hline \multicolumn{3}{|c|}{ A dear parent or a child death } & & & & 0.003 \\
\hline Yes & 42 & 61.76 & 26 & 38.24 & 68 & \\
\hline No & 333 & 43.42 & 434 & 56.58 & 767 & \\
\hline \multicolumn{2}{|c|}{ Abuse or rape in childhood } & & & & & 0.032 \\
\hline Yes & 39 & 35.45 & 71 & 64.55 & 110 & \\
\hline No & 336 & 46.34 & 389 & 53.66 & 725 & \\
\hline
\end{tabular}

Table 3. Distribution of expectant mothers according to the educational level, socioeconomic level and a previous spontaneous miscarriage, according to depression. (Parakou, 2018; $\mathrm{N}=835$ ).

\begin{tabular}{|c|c|c|c|c|c|c|}
\hline & \multicolumn{4}{|c|}{ DEPRESSION } & \multirow{3}{*}{$\begin{array}{c}\text { Total } \\
(\mathrm{N})\end{array}$} & \multirow{3}{*}{$p$} \\
\hline & \multicolumn{2}{|c|}{ Yes } & \multicolumn{2}{|c|}{ No } & & \\
\hline & $\mathrm{n}$ & $\%$ & $\mathrm{n}^{\prime}$ & $\%$ & & \\
\hline Educational Level & & & & & & 0.004 \\
\hline Out of school & 85 & 44.27 & 107 & 55.73 & 192 & \\
\hline
\end{tabular}




\section{Continued}

\begin{tabular}{|c|c|c|c|c|c|c|}
\hline Primary & 55 & 27.50 & 145 & 72.50 & 200 & \\
\hline Secondary & 131 & 36.09 & 232 & 63.91 & 363 & \\
\hline Higher & 24 & 30.00 & 56 & 70.00 & 80 & \\
\hline Socioeconomic level & & & & & & 0.000 \\
\hline Low & 198 & 37.36 & 332 & 62.64 & 530 & \\
\hline Average & 93 & 38.27 & 150 & 61.73 & 243 & \\
\hline High & 4 & 6.45 & 58 & 93.55 & 62 & \\
\hline Marital status & & & & & & 0.000 \\
\hline Single & 14 & 37.84 & 23 & 62.16 & 37 & \\
\hline Cohabitation & 91 & 21.82 & 326 & 78.18 & 417 & \\
\hline Married & 188 & 49.60 & 191 & 50.40 & 379 & \\
\hline Divorced & 1 & 100.00 & 0 & 0.00 & 1 & \\
\hline Widow & 1 & 100.00 & 0 & 0.00 & 1 & \\
\hline Spontaneous miscarriage & & & & & & 0.000 \\
\hline Yes & 100 & 58.82 & 70 & 41.18 & 170 & \\
\hline No & 74 & 27.82 & 192 & 72.18 & 266 & \\
\hline
\end{tabular}

Table 4. Distribution of expectant mothers by onset of previous induced abortion, gestational age, difficulties during the current pregnancy, alcohol consumption, according to depression (Parakou, 2018; $\mathrm{N}=835$ ).

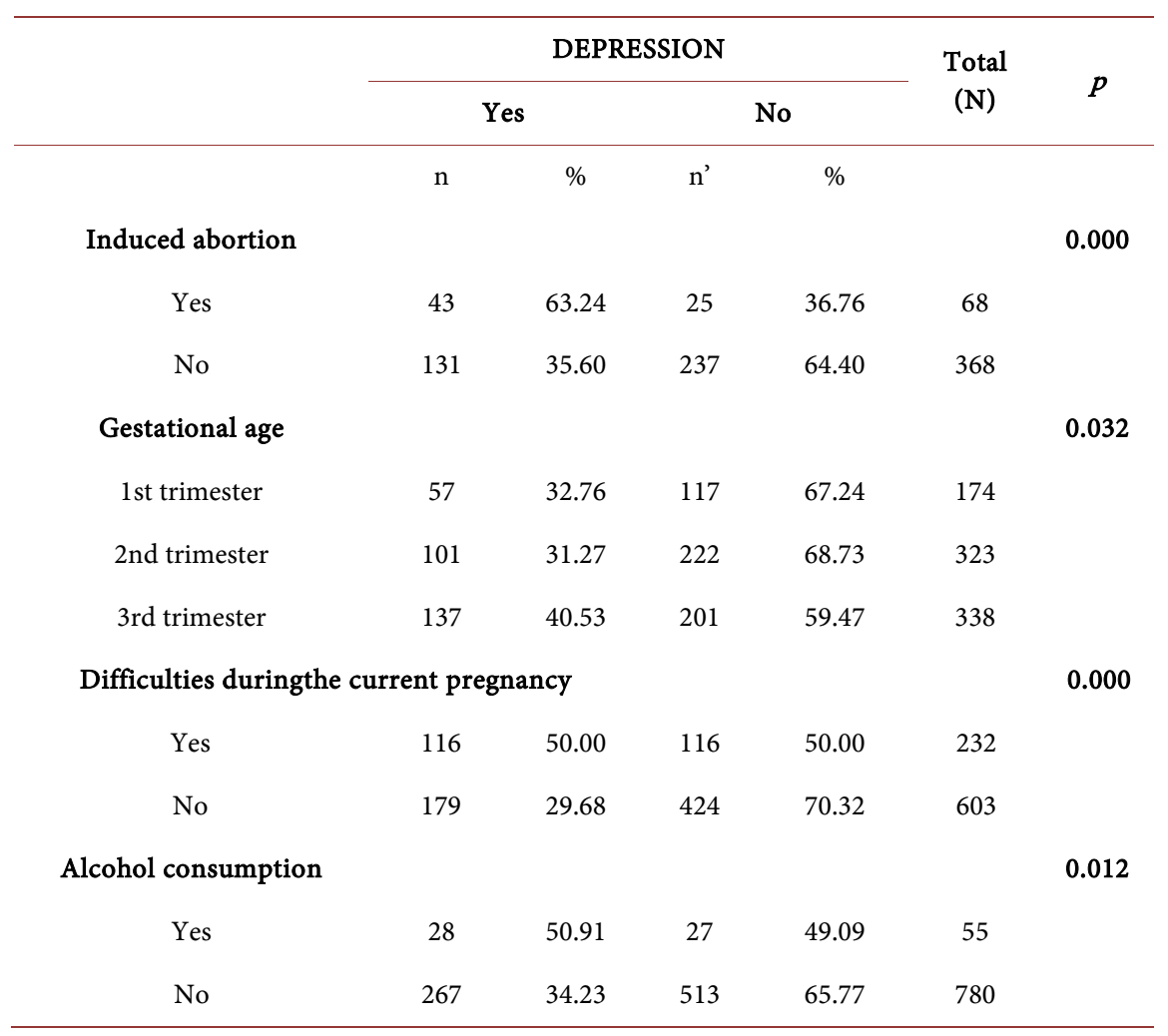


Table 5. Determinants of anxiety in encountered expectant mothers (Parakou, 2018; N = 835).

\begin{tabular}{|c|c|c|c|c|c|c|}
\hline & \multirow{2}{*}{$\mathrm{n}$} & \multicolumn{2}{|c|}{ ANXIETY } & \multirow{2}{*}{ OR } & \multirow{2}{*}{$\mathrm{IC}_{95 \%}$} & \multirow{2}{*}{$p$-value } \\
\hline & & Yes & $\%$ & & & \\
\hline \multicolumn{7}{|l|}{ Marital status } \\
\hline Single & 37 & 17 & 45.95 & 1.33 & $0.68-2.63$ & 0.397 \\
\hline Cohabitation & 417 & 162 & 38.85 & 1 & & \\
\hline Married & 379 & 195 & 51.45 & 1.66 & $1.25-2.21$ & 0.001 \\
\hline \multicolumn{7}{|l|}{ Socioeconomic level } \\
\hline Low & 530 & 251 & 47.36 & 6.07 & $2.83-13.00$ & 0.000 \\
\hline Average & 243 & 116 & 47.74 & 6.16 & $2.81-13.50$ & 0.000 \\
\hline High & 62 & 8 & 12.90 & 1 & & \\
\hline \multicolumn{7}{|l|}{ Profession } \\
\hline Official & 30 & 8 & 26.67 & 1 & & \\
\hline Private sector worker & 98 & 32 & 32.65 & 1.33 & $0.53-3.32$ & 0.535 \\
\hline Trader/ Reseller & 264 & 115 & 43.56 & 2.12 & $0.91-4.94$ & 0.075 \\
\hline Artisan & 226 & 108 & 47.79 & 2.51 & $1.07-5.89$ & 0.029 \\
\hline Pupil/Student & 92 & 45 & 48.91 & 2.63 & $1.06-6.51$ & 0.032 \\
\hline Unemployment & 113 & 60 & 53.10 & 3.11 & $1.27-7.57$ & 0.009 \\
\hline Others & 12 & 7 & 58.33 & 3.85 & $0.94-9.67$ & 0.053 \\
\hline \multicolumn{7}{|l|}{ Trimester of pregnancy } \\
\hline 1st trimester & 174 & 54 & 31.03 & 1 & & \\
\hline 2nd trimester & 323 & 143 & 44.27 & 1.76 & $1.19-2.60$ & 0.004 \\
\hline 3rd trimester & 338 & 178 & 52.66 & 2.47 & $1.68-3.64$ & 0.000 \\
\hline \multicolumn{7}{|l|}{ Spontaneous miscarriage } \\
\hline Yes & 170 & 50 & 29.41 & 0.51 & $0.34-0.77$ & 0.001 \\
\hline No & 266 & 119 & 44.74 & 1 & & \\
\hline \multicolumn{7}{|l|}{ Induced abortion } \\
\hline Yes & 68 & 18 & 26.47 & 0.52 & $0.29-0.92$ & 0.025 \\
\hline No & 368 & 151 & 41.03 & 1 & & \\
\hline \multicolumn{7}{|c|}{ Abuse or rape in childhood } \\
\hline Yes & 110 & 39 & 35.45 & 0.64 & $0.42-0.98$ & 0.039 \\
\hline No & 725 & 336 & 46.34 & 1 & & \\
\hline \multicolumn{7}{|c|}{ A close one or perinatal death } \\
\hline Yes & 68 & 42 & 61.76 & 2.10 & $1.26-3.50$ & 0.003 \\
\hline No & 767 & 333 & 43.42 & 1 & & \\
\hline \multicolumn{7}{|l|}{ Absence ofsocial support } \\
\hline Yes & 53 & 32 & 60.38 & 1.50 & $0.85-2.66$ & 0.157 \\
\hline No & 782 & 343 & 43.86 & 1 & & \\
\hline
\end{tabular}


Table 6. Determinants of depression inexpectant mothers (Parakou, 2018; $\mathrm{N}=835$ ).

\begin{tabular}{|c|c|c|c|c|c|c|}
\hline & \multirow{2}{*}{$\mathrm{n}$} & \multicolumn{2}{|c|}{ DEPRESSION } & \multirow{2}{*}{ OR } & \multirow{2}{*}{$\mathrm{IC}_{95 \%}$} & \multirow{2}{*}{$p$-value } \\
\hline & & Yes & $\%$ & & & \\
\hline \multicolumn{7}{|l|}{ Marital status } \\
\hline Single & 37 & 14 & 37.84 & 2.18 & $1.07-4.40$ & 0.026 \\
\hline Cohabitation & 417 & 91 & 21.82 & 1 & & \\
\hline Married & 379 & 188 & 49.60 & 3.52 & $2.59-4.79$ & 0.000 \\
\hline \multicolumn{7}{|l|}{ Educational level } \\
\hline Out of school & 192 & 85 & 44.27 & 1.85 & $1.06-3.23$ & 0.028 \\
\hline Primary & 200 & 55 & 27.50 & 0.88 & $0.50-1.56$ & 0.674 \\
\hline Secondary & 363 & 131 & 36.09 & 1.31 & $0.78-2.22$ & 0.301 \\
\hline Higher & 80 & 24 & 30.00 & 1 & & \\
\hline \multicolumn{7}{|c|}{ Socioeconomic level } \\
\hline Low & 530 & 198 & 37.36 & 8.64 & $3.09-17.18$ & 0.000 \\
\hline Average & 243 & 93 & 38.27 & 5.93 & $2.26-15.51$ & 0.000 \\
\hline High & 62 & 4 & 6.45 & 1 & & \\
\hline \multicolumn{7}{|c|}{ Spontaneous miscarriage } \\
\hline Yes & 170 & 100 & 58.82 & 3.70 & $2.46-5.56$ & 0.001 \\
\hline No & 266 & 74 & 27.82 & 1 & & \\
\hline \multicolumn{7}{|c|}{ Induced abortion } \\
\hline Yes & 68 & 43 & 63.24 & 3.11 & $1.81-5.32$ & 0.000 \\
\hline No & 368 & 131 & 35.60 & 1 & & \\
\hline \multicolumn{7}{|c|}{ Trimester of pregnancy } \\
\hline 1st trimester & 174 & 57 & 32.76 & 1.07 & $0.72-1.58$ & 0.733 \\
\hline 2nd trimester & 323 & 101 & 31.27 & 1 & & \\
\hline 3rd trimester & 338 & 137 & 40.53 & 1.49 & $1.08-2.06$ & 0.013 \\
\hline \multicolumn{7}{|c|}{ Difficulties during the current pregnancy } \\
\hline Yes & 232 & 116 & 50.00 & 2.36 & $1.73-3.23$ & 0.000 \\
\hline No & 603 & 179 & 29.68 & 1 & & \\
\hline \multicolumn{7}{|c|}{ Alcohol consumption } \\
\hline Yes & 55 & 28 & 50.91 & 1.99 & $1.15-3.44$ & 0.012 \\
\hline No & 780 & 267 & 34.23 & 1 & & \\
\hline
\end{tabular}

\section{Discussion}

\subsection{Limitations of the Study}

A depression screening strategy in expectant mothers should take into account the potential chronicity of depression symptoms through repeated assessment in 
order to provide an intervention to the vulnerable women.

\subsection{Prevalence of Anxiety and Depression}

\subsubsection{Prevalence of Anxiety}

The prevalence of anxiety disorders in expectant mothers was $44.91 \%$. Unemployed pregnant women were more affected (see Table 1). Studies on maternal anxiety prevalence reported rate from $12 \%$ to $59 \%$ during pregnancy [8] [9]. Basing on Hospital Anxiety and Depression Scale, Lee et al. [10] found a prevalence of anxiety close to $54 \%$ in a Chinese population. However, a lower prevalence of anxiety at $23 \%$ has been reported by Heyningen et al. [11], in South Africa basing on the Mini International Neuropsychiatric Interview scale. The variability of those prevalences confirm the extent of anxiety during pregnancy. All the authors agree with adverse effects of anxiety on the pregnancy outcome, mother-child interaction and the infant development. According to Capponi et al. [12], mothering approaches are modified by a high level of anxiety "even non pathological", and reflect in mother-child relationships quality. In general, the anxiety specific to pregnancy has numerous consequences on both mother and foetus [1].

\subsubsection{Prevalence of Depression}

Depressive syndrome prevalence in expectant mothers of Parakou was $35.33 \%$. The third trimester of pregnancy was more depressogenic (see Table 2). And marriage did not protect against depression (see Table 3 ). In a meta-analysis, Ayano et al. [13], reported a higher antenatal depression (32.10\%) during the third trimester of pregnancy. Although close to the prevalence found in Parakou, that number rather assesses depression particularly at the third trimester (see Table 4). By contrast, Duko et al. [14], reported $21.5 \%$ as prevalence after a similar study in Ethiopia. Basing on Life Event Scale for Pregnancy Women (LESPW) to assess stress at 12 - 16 weeks of pregnancy and at 32 - 36 weeks of pregnancy, $11.1 \%$ and $10.3 \%$ of expectant mothers developed respectively anxiety and depressive mood in Shanghai MCPC District [15]. The fluctuation of depression prevalences reported in expectant mothers is related to the different tools and the threshold values used.

\subsection{Social Determinants of Anxiety and Depression in Expectant Mothers at Parakou}

\subsubsection{Deficit in Education and Economic Resources}

Lack of education (OR 1.85; $\left.\mathrm{IC}_{95 \%}[1.06-3.23] ; p=0.028\right)$ and low socioeconomic level (OR 8.643; $\mathrm{IC}_{95 \%}$ [09 - 17.18]; $p=0.00$ ), have been identified as risk factors for depression in expectant mothers at Parakou (see Table 1 and Table 5). Unemployed expectant mothers are mostly dependent on their partner/spouse and could suffer from deprivation. Van Heyningen et al. [11], observed that a high social support seemed to reduce the risk for prenatal anxiety in South African expectant mothers who had a low income (OR 0.95; $\mathrm{IC}_{95 \%}[0.91-0.99]$ ). 
Therefore, a good socioeconomic level protects from anxiety and depression during pregnancy [16]. Kinser et al. [17], reported the income and stressful events as the most important predictors of depression during pregnancy.

Educational levels in the sample varied. The majority had a secondary level (47\%). Chan et al. [18] found similar results in China in 2013 (52.4\%). Silva et al. [19], also got the same results (41.1\%) in Brazil, in 2017. Whereas Giardinelli et al. [16] reported almost the same frequencies of both secondary (47\%) and high level (46.4\%) in Italy in 2012. That difference with the observations made at Parakou is due to the fact that this study has been conducted only in public maternities which are not frequented by intellectual expectant mothers.

\subsubsection{Celibacy as Risk of Developing Anxiety and Depression in Pregnancy}

In the multivariate logistic regression, celibacy was a risk factor (celibacy: $\mathrm{OR}=$ 2.18; $\mathrm{IC}_{95 \%}[1.07-4.40] ; p=0.026$ ) for depression in expectant mothers (see Table 6). Räisänen et al., [20] in Finland (2014), achieved the same conclusions; (celibacy: $\mathrm{OR}=2.86 ; \mathrm{IC}_{95 \%}[2.62-3.11]$ ). Besides Weobong et al. in Ghana [21] and Duko et al., [14], reported the lack of social support as a factor significantly associated with depression in pregnancy. So, single expectant mothers can be considered as vulnerable because of their poor support.

\subsubsection{Gynaecological and Obstetrical Factors}

The risk of developing anxiety during the third trimester of pregnancy is 2.47 times higher $\left(\mathrm{OR}=2.47 ; \mathrm{IC}_{95 \%}[1.68-3.64] ; p=0.000\right)$ than the one at the 1st trimester (see Table 5). The third trimester is for sure very critical for the management of risky pregnancies. Moreover, the third trimester is the period in which the expectant mother intensively lives the problem of "imaginary/real child" before the childbirth.

A previous spontaneous miscarriage potentiates 3.70 times $\left(\mathrm{OR}=3.70\right.$; $\mathrm{IC}_{95 \%}$ [2.46 - 5.56]; $p=0.001$ ) the risk of developing depression during pregnancy in expectant mothers at Parakou. Zhu et al. [22], in Singapore (2018) found a similar result $\left(\mathrm{OR}=2.70 ; \mathrm{IC}_{95 \%}[1.55-4.71] ; p<0.001\right)$. A previous induced abortion had the same potential risk for the onset of depression in pregnancy $(\mathrm{OR}=3.11$; $\left.\mathrm{IC}_{95 \%}[1.81-5.32] ; p=0.000\right)$. Pregnancy in women is a particular moment for the recurrence of past traumas and bereavements. Here, the underlying psychological constructions for the bereavement are the same [23]. In retrospective and observational study using a large sample including 38,000 pregnancies, Wallwiener et al. [24], reported $9.3 \%$ of depression and $16.9 \%$ of anxiety disorders.

\subsubsection{Stressful Life Event and Alcoholism during Pregnancy}

A close one or a perinatal death during pregnancy was a risk factor for anxiety (see Table 5). It increases 2.10 times $\left(0 \mathrm{R}=2.10 \mathrm{IC}_{95 \%}[1.26-3.50] ; p=0.003\right)$ the risk of developing anxiety during pregnancy. Van Heyningen et al. [11], in South Africa (2017), made the same observation. All those losses assimilated to 
stressful events had been identified by Bayrampour et al. [25] as predictive factors of anxiety and depression during pregnancy. Alcohol consumption (see Table 6) during pregnancy, was associated with a higher risk of depressive mood $\left(\mathrm{OR}=1.99 ; \mathrm{IC}_{95 \%}[1.15-3.44] ; p=0.012\right)$. This study doesn't provide information on the impact of maternal addiction to alcohol on the foetus. Easey et al. [26], reported through a meta-analysis, a positive association between prenatal exposure to alcohol and children with mental health problems proved by more than half of analysis.

\section{Conclusion}

The risk factors found during pregnancy such as: single status, low educational level, low socioeconomic level are to be considered as true social determinants of anxiety and depression during pregnancy. They have harmful consequences on the mother and her child. Past history of spontaneous miscarriage or induced abortion, stressful life events; all those difficulties during pregnancy lead expectant mothers to alcohol consumption without regard for its damage for the unborn child. The implementation of social support seems necessary in order to help and accompany women suffering from anxiety and depression during the perinatal period.

\section{Conflicts of Interest}

The authors declare no conflicts of interest regarding the publication of this paper.

\section{References}

[1] Reymond, C., Derguy, C., Wendland, J. and Loyal, D. (2019) Validation française d'une échelle d'anxiété spécifique à la grossesse (PRAQ-R2). Pratiques Psychologiques. https://doi.org/10.1016/j.prps.2018.11.008

[2] Mourabbih, M., Serhier, Z., Arazakou, M., Agoub, M. and Bennani, M.O. (2017) Prévalence de la dépression et de l'anxiété en fin de grossesse au Maroc. Revue d Épidémiologie et de Santé Publique, 65, S84. https://doi.org/10.1016/j.respe.2017.03.078

[3] Gourine, M., Abdelouahab, A., Arrar, M., Cherrak, A., Halimi, S. and Belhadj, M. (2019) Facteurs associés à la dépression chez la femme diabétique de type 2: Etude cas-témoin. Médecine des maladies Métaboliques, 9, 418-422. https://doi.org/10.1016/S1957-2557(15)30151-6

[4] Lambert, M. and Gressier, F. (2019) Biomarqueurs de L'inflammation et Dépression du Post-Partum. Une Revue Systématique De la Littérature. The Canadian Journal of Psychiatry. https://doi.org/10.1177/0706743719828970

[5] Guille, C. and Newman, R. (2018) Perinatal Mental Health: An Issue of Obstetrics and Gynecology Clinics Vol. 45-3. Elsevier, Amsterdam. https://doi.org/10.1016/S0889-8545(18)30053-6

[6] UNICEF (2011) Enquête modulaire intégrée sur les conditions de vie des ménages Cotonou.

[7] General Assembly of the World Medical Association (2014) World Medical Associa- 
tion Declaration of Helsinki: Ethical Principles for Medical Research Involving Human Subjects. Journal of the American College of Dentists, 81, 14-18. https://www.ncbi.nlm.nih.gov/pubmed/25951678

[8] Skari, H., Skreden, M., Malt, U.F., Dalholt, M., Ostensen, A.B., Egeland, T. and Emblem, R. (2002) Comparative Levels of Psychological Distress, Stress Symptoms, Depression and Anxiety after Childbirth; A Prospective Population-Based Study of Mothers and Fathers. BJOG: An International Journal of Obstetrics and Gynaecology, 109, 1154-1163. https://doi.org/10.1111/j.1471-0528.2002.00468.x

[9] Faisal-Cury, A. and Rossi Menezes, P. (2007) Prevalence of Anxiety and Depression during Pregnancy in a Private Setting Sample. Archives of Women's Mental Health, 10, 25-32. https://doi.org/10.1007/s00737-006-0164-6

[10] Lee, A.M., Lam, S.K., SzeMun Lau, S.M., Chong, C.S.Y., Chui, H.W. and Fong, D.Y.T. (2007) Prevalence, Course, and Risk Factors for Antenatal Anxiety and Depression. Obstetrics \& Gynecology, 110, 1102-1112. https://doi.org/10.1097/01.AOG.0000287065.59491.70

[11] van Heyningen, T., Honikman, S., Myer, L., Onah, M.N., Field, S. and Tomlinson, M. (2017) Prevalence and Predictors of Anxiety Disorders amongst Low-Income Pregnant Women in Urban South Africa: A Cross-Sectional Study. Archives of Women's Mental Health, 20, 765-775. https://doi.org/10.1007/s00737-017-0768-z

[12] Capponi, I., Bacro, F. and HalimBoudoukha, A. (2013) Effets différentiels des types de soutien social sur l'anxiété maternelle périnatale. Bulletin de Psychologie, 525, 209-224. https://doi.org/10.3917/bupsy.525.0209

[13] Ayano, G., Tesfaw, G. and Shumet, S. (2019) Prevalence and Determinants of Antenatal Depression in Ethiopia: A Systematic Review and Meta-Analysis. PLoS ONE, 14, e0211764. https://doi.org/10.1371/journal.pone.0211764

[14] Duko, B., Ayano, G. and Bedaso, A. (2019) Depression among Pregnant Women and Associated Factors in Hawassa City, Ethiopia: An Institution-Based Cross-Sectional Study. Reproductive Health, 16, 2. https://doi.org/10.1186/s12978-019-0685-X

[15] Ma, X., Wang, Y., Hu, H., Tao, X.G., Zhang, Y. and Shi, H. (2019) The Impact of Resilience on Prenatal Anxiety and Depression among Pregnant Women in Shanghai. Journal of Affective Disorders, 250, 57-64. https://doi.org/10.1016/j.jad.2019.02.058

[16] Giardinelli, L., Innocenti, A., Benni, L., Stefanini, M.C., Lino, G., Lunardi, C. and Faravelli, C. (2012) Depression and Anxiety in Perinatal Period: Prevalence and Risk Factors in an Italian Sample. Archives of Women's Mental Health, 15, 21-30. https://doi.org/10.1007/s00737-011-0249-8

[17] Kinser, P.A., Thacker, L.R., Lapato, D., Wagner, S., Roberson-Nay, R., Jobe-Shields, L. and York, T.P. (2018) Depressive Symptom Prevalence and Predictors in the First Half of Pregnancy. Journal of Women's Health, 27, 369-376. https://doi.org/10.1089/jwh.2017.6426

[18] Chan, C.Y., Lee, A.M., Lam, S.K., Lee, C.P., Leung, K.Y., Koh, Y.W., et al. (2013) Antenatal Anxiety in the First Trimester: Risk Factors and Effects on Anxiety and Depression in the Third Trimester and 6-Week Postpartum. Open Journal of Psychiatry, 3, 301-310. https://doi.org/10.4236/ojpsych.2013.33030

[19] Silva, M.M.D.J., Nogueira, D.A., Clapis, M.J. and Leite, E.P.R. (2017) Anxiety in Pregnancy: Prevalence and Associated Factors. Revista da Escola de Enfermagem da USP, 51, e03253. https://doi.org/10.1590/s1980-220x2016048003253

[20] Räisänen, S., Lehto, S.M., Nielsen, H.S., Gissler, M., Kramer, M.R. and Heinonen, S. (2014) Risk Factors for and Perinatal Outcomes of Major Depression during Pregnancy: A Population-Based Analysis during 2002-2010 in Finland. BMJ Open, 4, 
e004883. https://doi.org/10.1136/bmjopen-2014-004883

[21] Weobong, B., Soremekun, S., ten Asbroek, A.H., Amenga-Etego, S., Danso, S., Owusu-Agyei, S. and Kirkwood, B.R. (2014) Prevalence and Determinants of Antenatal Depression among Pregnant Women in a Predominantly Rural Population in Ghana: The DON Population-Based Study. Journal of Affective Disorders, 165, 1-7. https://doi.org/10.1016/j.jad.2014.04.009

[22] Zhu, C.S., Tan, T.C., Chen, H.Y., Malhotra, R., Allen, J.C. and Østbye, T. (2018) Threatened Miscarriage and Depressive and Anxiety Symptoms among Women and Partners in Early Pregnancy. Journal of Affective Disorders, 237, 1-9. https://doi.org/10.1016/j.jad.2018.04.012

[23] Jaffe, J. (2017) Reproductive Trauma: Psychotherapy for Pregnancy Loss and Infertility Clients from a Reproductive Story Perspective. Psychotherapy, 54, 380. https://doi.org/10.1037/pst0000125

[24] Wallwiener, S., Goetz, M., Lanfer, A., Gillessen, A., Suling, M., Feisst, M. and Wallwiener, M. (2019) Epidemiology of Mental Disorders during Pregnancy and Link to Birth Outcome: A Large-Scale Retrospective Observational Database Study Including 38,000 Pregnancies. Archives of Gynecology and Obstetrics, 299, 755-763. https://doi.org/10.1007/s00404-019-05075-2

[25] Bayrampour, H., McDonald, S. and Tough, S. (2015) Risk Factors of Transient and Persistent Anxiety during Pregnancy. Midwifery, 31, 582-589.

https://doi.org/10.1016/j.midw.2015.02.009

[26] Easey, K.E., Dyer, M.L., Timpson, N.J. and Munafò, M.R. (2019) Prenatal Alcohol Exposure and Offspring Mental Health: A Systematic Review. Drug and Alcohol Dependence, 197, 344-353. https://doi.org/10.31234/osf.io/yk865 